\title{
Relationship between cardiovascular evaluation data on admission and secondary adverse cardiac event rate after acute coronary syndrome
}

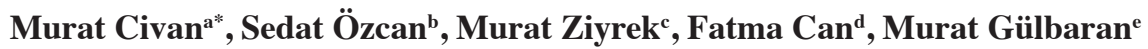 \\ ${ }^{a}$ Department of Cardiology, Kaçkar State Hospital, Rize, Turkey \\ ${ }^{b}$ Department of Cardiovascular Surgery, Faculty of Medicine, Çanakkale Onsekiz, Mart University, Çanakkale, Turkey \\ ${ }^{c}$ Department of Cardiology, Trabzon Karadeniz Hospital, Trabzon, Turkey \\ ${ }^{d}$ Department of Cardiology, Hopa State Hospital, Artvin, Turkey \\ ${ }^{e}$ Department of Cardiology, Şişli Florence Nightingale University, Istanbul, Turkey
}

\section{ARTICLE INFO}

\section{Article History}

Received $\quad 30 / 10 / 2013$

Accepted $\quad 08 / 06 / 2014$

\section{* Correspondence to:}

Murat Civan

Department of Cardiology,

Kaçkar State Hospital

Rize, Turkey

e-mail: civancivan@yahoo.com

\section{Keywords:}

Acute coronary syndrome

Mean platelet volume

QT dispersion

Secondary

\section{ABSTRACT}

The current study aimed to investigate the relationship of clinical data with mean platelet volume (MPV) and QT dispersion values on admission of acute coronary syndrome (ACS) patients to the adverse cardiac event rate in a follow-up period of 20 months after discharge. For this purpose demographic and clinical data with corrected QT dispersion on admission and MPV values of 97 consequtive patients with ACS were recorded, retrospectively. Their history of major adverse cardiac event (MACE) in a 20 months period after ACS was obtained from the hospital records, interviews with the attending physicians and telephone calls to patients. Demographic and clinical data with corrected QT dispersion on admission, and MPV values were compared between groups with and without MACE in terms of statistical significance. In our study, diabetesmellitus, left ventricular ejection fraction (EF) and wall motion score index (WMSI), corrected QT dispersion, total cholesterol, LDL, CK-MB and troponin levels were found significantly related to the secondary MACE rate ( $p$ values; 0.046, 0.0001, 0.0001, 0.032, 0.024, 0.002 and 0.0001 , respectively). No significant relation was detected between groups with and without MACE in terms of conservative medical follow-up and revascularization history $(\mathrm{p}=0.774)$. In the comparison of mean MPV values, there was no statistically significant difference between MPV values of patients with MACE $(10.4 \pm 1.8 \mathrm{fl})$ and without MACE $(10.3 \pm 2 \mathrm{fl})(\mathrm{p}=0.799)$. In addition, the subgroup analysis on acute ST-elevation myocardial infarction cases in our study group did not state a significant relationship between MPV values below/above $10.3 \mathrm{fl}$ and MACE rates ( $\mathrm{p}=0.774)$.

Finally, this retrospective study showed that corrected QT dispersion, diabetes, contractile reserve of left ventricule, total and LDL- cholesterol and peak cardiac enzyme values assessed during ACS might predict MACE.

J. Exp. Clin. Med., 2014; 31:81-85

(C) 2014 OMU

\section{Introduction}

Stenosis or occlusion of coronary arteries by atheromatous plaques is defined as coronary artery disease. Atherosclerosis starts to develope in early life and may progress to serious vascular pathologies. This group of diseases is one of the major causes of mortality and morbidity worldwide (Libby, P., 2000).

Thrombocytes, which are known to have important roles in acute myocardial infarction and atherothrombosis, have heterogenous size, density and activity. Changes in those parameters may be related to the trigger mechanism of acute coronary syndrome or spread of intravascular thrombus. Large thrombocytes are more adhesive and tend toward to male stronger agregation than the small ones. Increased in thrombocyte volume, on the other hand, causes a more prothrombotic state on atherosclerotic plaque and lead to higher risk of intracoronary thrombus (Davies and Thomas, 1984; Schoene, 1997).

The most important cause of sudden cardiac death is cardiac arrythmia including ventricular tachycardia and 
ventricular fibrillation (Jain and Avasthi, 2004). Patients with long QT have also heterogenous action potentials and it favors ventricular fibrillation. QT dispersion shows this heterogeneity and is calculated by surface ECG. High QT dispersion values were associated with fatal arrythmia and sudden death in most diseases (Day et al., 1990; Van dee Loo et al., 1994; Somberg and Molnar, 2002).

Studies regarding the relation between mean platelet volume and arrythmia are rare and focus on atrial fibrillation. Patients with paroxysmal atrial fibrillation (AF), in particular, had high mean platelet volume (MPV) (Colkesen et al., 2008). However, studies regarding the relation between MPV/QT dispersion and adverse secondary cardiac events are inadequate (Kuch et al., 2009). We analyzed some demographic and clinical data of patients with ACS and relation to the secondary adverse cardiac events.

\section{Experimental Procedure}

Our study designed a cross-sectional and retrospective study, which was approved by the local ethics committee. Our study population was composed of 13 female and 84 male patients, who admitted with chest pain between October 2009 and December 2009, and diagnosed as acute coronary syndrome consequtively due to their clinical and electrocardiographical findings. Patients underwent one of three treatment strategies, namely percutaneous coronary intervention, coronary arterial by-pass grafting or medical follow-up. Patients included in our study were reviewed from the hospital records in terms of their detailed history, risk factors, biochemical findings and echocardiography/ECG in the first 24 hours and medications prescribed on discharge. Only their peak cardiac enzyme levels were taken into account. MPV was recorded from the first hemogram test on admission. Major adverse cardiac events (MACE) were defined as death, ventricular arrythmia and restenosis on the target lesion more than $60 \%$ and/or myocardial infarction. Initially, hospital records of 20 months follow-up were reviewed to search MACEs. About cases without any MACE record, information was requested from their physician or directly from themselves via telephone calls to reveal recent hospitalizations or interventions. Patients with MACE were compared to those of without MACE in terms of demographic/clinical features, MPV and corrected QTd.

All 12-channel ECG records on admission were taken with a $25 \mathrm{~mm} / \mathrm{sc}$ velocity and $10 \mathrm{~mm} / \mathrm{mV}$ calibration. QT interval was measured from the beginning of $\mathrm{Q}$ wave to the end of $\mathrm{T}$ wave on the isoelectric line in miliseconds. In case of $\mathrm{U}$ wave, the lowest point between $\mathrm{T}$ and $\mathrm{U}$ waves was accepted as the end of $\mathrm{T}$ wave. Heart rate-corrected QT interval was calculated with Bazzet Formula (Özgül et al., 2007). Corrected QTd was measured by calculating the difference between the longest and shortest QTc of each patient. Corrected QTds above $50 \mathrm{mls}$ were regarded as abnormal. All measurements were performed manually by the same researcher to avoid interobserver variability. Intraobserver variability was not assessed.

Patients diagnosed with any infection or electrolite disturbance on the day of admission, presented with bradyarrythmia or tachyarrythmia, having an ECG with bundle branch block or atrial fibrillation or taking medications affecting QT interval were excluded from the study. For the statistical analysis, SPSS for Windows version 17.0 was used. In addition to definitive statistical methods (Mean ,Standard deviation etc.), Man-Whitney U test was used for the evaluation of quantitative data and Ki-square /Fisher tests were used for proportional data. Results were assessed in a confidence interval of $95 \%$ with the significance criteria of $\mathrm{p}<0.05$.

\section{Results}

In our study population diagnosed with acute coronary syndrome, ages ranged between 33 and 88 years (mean age; $61.1 \pm 26.9$ years). On the other hand, patients with a MACE were between 40 and 88 years of age (mean age; $61.8 \pm 26.6$ years). Mean MACE-free period was found as 389.04 \pm 253.6 days (ranged between 6 and 603 days). There was no statistical significance in terms of age and gender difference between MACE and non-MACE groups (p values were 0.382 and 0.286 , respectively). Clinical and demographic features of both groups are shown in Table 1.

Diabetes, total cholesterol, LDL, CK-MB and Troponin-T levels were positively correlated with developement of MACE ( $\mathrm{P}$ values were 0.046, 0.032, 0.024, 0.002 and 0.0001 , respectively). Patients diagnosed with acute coronary syndrome (ACS) were composed of 43 cases of unstable angina (USAP, 44.3\%), 20 cases of non-ST elevation ACS (NST-ACS, 20.6\%) and 34 cases of myocardial infarction with ST elevation (STEMI, 35.1\%). Of those, 76 patients underwent PTCA and stenting (78.4\%), and 11 patients were

Table 1. Distribution of clinical and demographic features in MACE and non-MACE groups

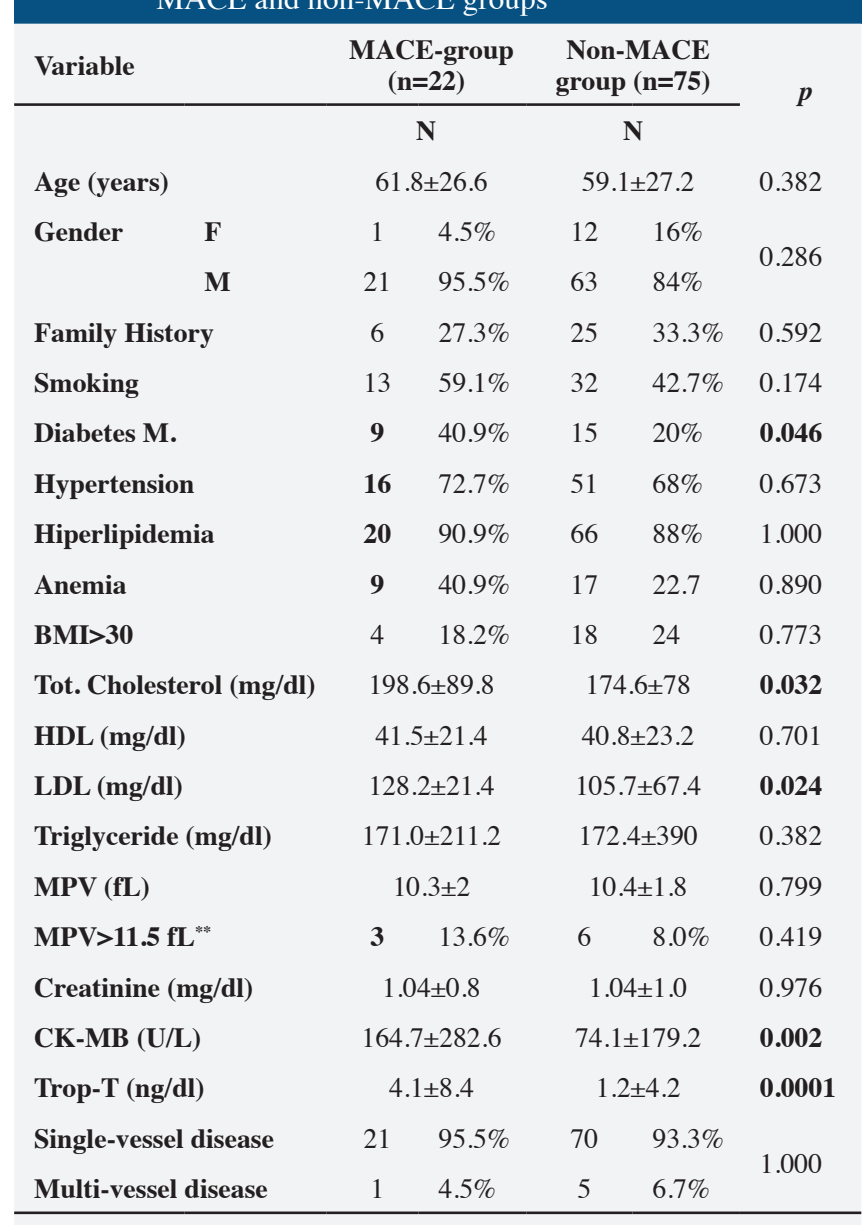

*Body Mass Index, **11.5 fL is the mean MPV value of study population 
operated for immediate coronary artery by-pass grafting. Coronary lesions of 10 patients $(10.3 \%)$ were not convenient for any intervention and followed up with conservative medical treatment. During their 20 months follow-up period, there was no MACE in $77.3 \%$ of patients. On the other hand, $5.2 \%$ of cases died due to cardiovascular events, restenosis or MI developed on the previous lesions in $16.5 \%$, and one of the patients $(1 \%)$ was hospitalized due to recurrent ventricular tachycardia episodes. There was no significant difference between MACE and non-MACE groups in terms of revascularization and conservative medical treatment rates $(\mathrm{p}=0.447)$.

In MACE group, left ventricular mean ejection fractions (EF) calculated by Simpson method after the ACS and wall motion score index (WMSI) were compared with those of non-MACE group. Mean EF of MACE group (EF:41.2\% \pm 14.2$)$ and WMSI were lower than that of nonMACE group (EF:49.7\% \pm 16.2 ), which were statistically significant $(\mathrm{p}=0.001)$. Moreover, left ventricular aneurysms after ACS were more frequently encountered in MACE group $(\mathrm{p}=0.001)$.

When MPV values on admission of two groups were compared to each other, MPV of MACE $(10.4 \pm 1.8 \mathrm{fL})$ and non-MACE groups $(10.3 \pm 2 \mathrm{fL})$ did not differ significantly $(\mathrm{p}=0.799)$ (Fig. 2). Similarly, subgroup analysis of acute STEMI cases in our study population revealed that there was no significant relationship between groups in terms of MPV levels below or above $10.3 \mathrm{fL}(\mathrm{p}=0.774)$. In addition, MACEfree periods of MACE group $(n=22)$ were not related to their MPV values being below or above $11.5 \mathrm{fL}$ (upper limit of MPV reference range) $(\mathrm{p}=0.363)$.

When mean QT dispersions of two groups were compared to each other (Fig. 3), mean QTd of non-MACE group $(33.2 \pm 32 \mathrm{~ms})$ was significantly lower than that of MACE group $(49.5 \pm 23.8 \mathrm{~ms})(\mathrm{p}=0.001)$.

There was no significant difference between MACE- and non-MACE groups in terms of statin, clopidogrel, angiotensin converting enzyme (ACE) inhibitor, acetylsalisylic acid (ASA) and $\beta$-blocker usage ( $\mathrm{p}$ values; 0.708, 1.0, 0.205, 0.619 and 0.74 , respectively).

\section{Discussion}

Our study showed that cQTd values of MACE group calculated retrospectively from ECG on admission were significantly higher than that of non-MACE group. In addition, diabetes, total cholesterol, LDL, CK-MB and troponin-T levels were

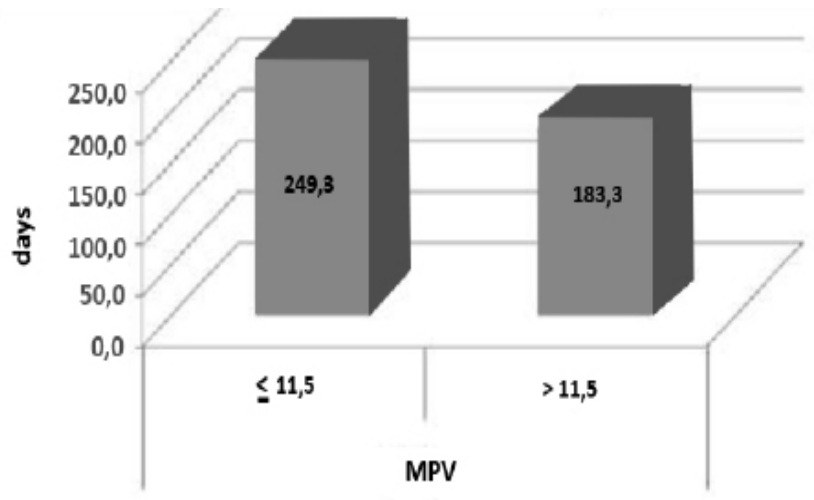

Fig. 1. Relation between cases in MACE group or high MPV values and their MACE-free periods.

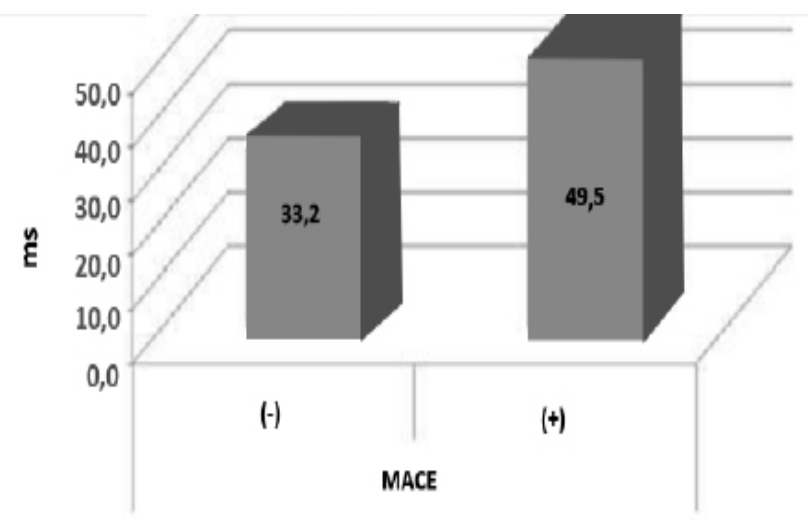

Fig. 2. Distribution of QT dispersions in MACE and non-MACE groups.

all also positively correlated with developement of MACE. Despite a mild increase in MPV values of admission, MPV had no statistically significant relation with MACE rates.

Variability of QT interval, which is called QTd, is thought to reflect regional differences during the repolarization process (Schwartz et al., 1975; Day et al., 1990; Özgül et al., 2007). Many studies showed that QTd is a predictor of short term ventricular arrythmia and mortality after acute myocardial infarction (Van de Loo et al., 1994; Jain and Avasthi, 2004). Zaputovic et al (1997) reported in their study that cQTd of patients with major ventricular arrythmia in the first 24 hours after acute MI were significantly longer than that of patients without VT/VF. This significance was not strong in cQT interval. Wang et al (2002) also revealed that cQTd above $60 \mathrm{~ms}$ calculated from the first and third day ECG of patients with uremia and acute MI was associated with increased mortality in the following year. In the study of Bodi et al (2001) which evaluated the relationship between QT dispersions during the follow-up and prognosis in six months after myocardial infarction, however, no significant relationship was detected between cQTd, ejection fraction after MI and MACE rates in six months follow-up, despite a shortened cQTd in the course of time. The highly significant relationship of cQTd with MACE rates during the followup of our study may be provided by the study design. This significance may be anticipated as our study population contained all of three ACS subtypes (USAP, NST-ACS and STEMI) and, as both MACE rates and cQTd values were mostly found high in STEMI cases of several clinical trials such as Paventi et al (1999) and others.

Thrombocytes with large size produced in bone marrow are released to the circulation before their maturation as they are consumed rapidly during acute coronary syndromes (Libby, 2000). Rapidly produced ones have an higher mean volume. In addition, elevated MPV may be caused by early consumption of thrombocytes with small volume during acute coronary syndromes (Trowbridge et al., 1985). In the study of Huczek et al. (2005), MPVs measured during acute MI had an highly significant relationship with increased mortality in following six months and increased number of no-reflow cases during primary PTCA. Also other researches showed significant associations between MPV values measured during acute STEMI and long term prognosis (Yang et al, 2006). In our study, on the other hand, there was no significant relationship between MPV and MACE rates despite a mild elevation in MPV values. Also a subgroup analysis of our 
acute STEMI cases $(n=34)$ revealed no significant relation when comparing MPV values below and above $10.3 \mathrm{fL}$ with MACE occurance. Comparison of MACE-free interval of MACE group with MPV values showed no statistical significance. This result may be explained with inadequate size of our study population.

Dutcher et al (2007) found that no statistical significance for LVEF alone in prediction of two and five years mortality after acute STEMI. However, exercise capacity <4 METs was highly significant and concurrent usage of both parameters was shown to be a stronger predictor. In the study of Gottlieb et al. (1992) which followed up 1850 acute STEMI patients for two years, LVEF and degree of pulmonary congestion on discharge were detected to be closely related to mortality. In our study, LVEF values, WMSI index and presence of aneurisms were also found related to MACE occurance, significantly.

Multivariate analysis of risk factors in the study of Kodama et al (1996) yielded diabetes as the most important non-cardiac risk factor to predict short term prognosis of acute MI patients. Similarly, diabetes was found to be significantly related to MACE development in our study.

Although pravastatin treatment to lower LDL levels after acute MI in CARE trial (Lewis et al., 1998) decreased MACE rates in five years follow-up significantly, recently declared KAMIR registry (Kyung et al., 2010) with 9571 cases suggested that high LDL levels during acute MI is not an independent risk factor for 12 months mortality. On the other hand, Malmberg et al. (1994) reported that high LDL levels on admission had a significant relationship with reinfarction in six to nine years follow-up. Also our study revealed a statistically significant relation between initial LDL levels and development of MACE.

The study of Gruber et al. (2007) which analized risk factors of secondary cardiac hospitalizations after acute STEMI showed that high total cholesterol and urea levels on admission were strongly related to MACE development. Elevated initial total cholesterol levels in our study had also a significant relation to MACE rates.

PRIAMHO II registry of Aros et al (2006) and other studies (Elwood and Sweetnam, 1979; COMMIT, 2005; De Luca et al., 2006; Banerjee et al., 2008; Bonde et al., 2010) proved that B-blokers, statins, clopidogrel, acetylsalisylic acid and ACE inhibitors prescribed on discharge lowered the mortality and MACE rates of first year, significantly. As these medications were prescribed to all ACS patients of our study in accordance to indications and contraindications, no significant difference was found between medical treatment strategies of MACE and non-MACE groups.

When comparing treatment approaches, there was no significant difference between MACE and non-MACE groups in terms of conservative medical treatment and revascularization. A post hoc analysis of a recently declared trial (Lopes et al., 2008) performed on ACS patients showed that PTCA causes less common postoperative strokes, MIs, severe hemorrhages and renal damage than $\mathrm{CABG}$ in patients with intermediate or high risk multi-vessel disease despite similar mortality rates in first year. However, recurrent revascularization rates were higher in PTCA group. Another study (Rodriguez et al., 2001) compared patients who underwent early invasive procedures of PTCA and CABG with the ones who had selective invasive procedures after a period of follow-up, and found no significant difference in terms of MI and death during a five years follow-up. Despite its small population, our study also complies with these studies due to absence of a significant relationship between MACE rates of treatment groups.

Some clinical and demographic features on admission with acute coronary syndrome may be beneficial to predict MACE risk in follow-up period. QTd is an important parameter calculated easily on surface ECG records of patients and it predicts short term risk of ventricular arrythmia. Prospective and randomised studies on this topic are needed.

Study Limitations: All ECG records were taken at a rate of $25 \mathrm{~mm} / \mathrm{sec}$, which was inconvenient for an optimum manual QT measurement and irrecoverable due to retrospective nature of the study. In addition, some correlation and subgroup analyses of our study might yield non-significant results due to its relatively small sample size.

\section{Acknowledgements}

The authors are thankful to Istanbul Bilim University and Şişli Florence Nightingale Hospital for providing the necessary facilities for the preparation of the paper.

\section{REFERENCES}

Arós, F., Osorio, A.L.,Vila, J., Bescós, L.L., Cuñat, J., 2006. Effect of combined beta-blocker and angiotensin-converting enzyme 1nhibitor treatment on 1-year survival after acute myocardial infarction: Findings of the PRIAMHO-II Registry. Rev. Esp. Cardiol. 59, 313-320.

Banerjee, S., Varghese, C., Samuel, J., Weideman, R.A., Little, B.B., Kevin, C., 2008. Comparison of the 1mpact of short (<) and long-term ( $\geq 1$ year) clopidogrel use following percutaneous coronary intervention on mortality. Am. J. Cardiol. 102, 1159-1162. doi: 10.1016/j.amjcard.2008.06.058.

Bodi, V., Sanchis, J., Navarro A., Plancha, E., Chorro, F., 2001. QT dispersion within the first 6 months after an acute myocardial infarction: Relationship with systolic function, left ventricular volumes, infarct related artery status and clinical outcome Int. J. Cardiol. 80, 37-45.

Bonde, L., Sorensen, R., Fosbol, E.L., Abildstrom, S.Z., Hansen, P.R., Kober, L., Schramm, T.K., Weeke, P., Olesen, J., Torp-Pedersen, C., Gislason, G.H., 2010. Increased mortality associated with low use of clopidogrel in patients with heart failure and acute myocardial infarction not undergoing percutaneous coronary intervention: A nationwide study. J. Am. Col. Cardiol. 55, 1300-1307

Colkesen, Y., T. Acil, B., Abayli, F., Yigit, T., Katircibasi, T., Kocum, S., Demircan, A., Sezgin, B., Ozin, H., Muderrisoglu, 2008. Mean platelet volume is elevated during paroxysmal atrial fibrillation: A marker of increased platelet activation? Blood Coagul. Fibrinolysis. 19, 411-414. doi: 10.1097/MBC.0b013e3283049697.

COMMIT (Clopidogrel and Metoprolol in Myocardial Infarction Trial) collaborative group, 2005. Addition of clopidogrel to aspirin in 45852 patients with acute myocardial infarction: randomised placebo-controlled trial. Lancet. 366, 1607-1621.

Davies, M.J., Thomas, A.C., 1984. Thrombosis and acute coronary artery lesions in sudden cardiac ischemic death. N. Engl. J. Med. 310, 11371140 . 
Day, C.P., McComb, J.M., Campbell, R.W., 1990. QT dispersion: An indication of arryhtmia risk in patients with long QT intervals. Br. Heart. $63,342-344$.

De Luca, G., Suryapranata, H., Ottervanger, J.P., Van't Hof, A.W., Hoorntje, J.C., Gosselink, A.T., Dambrink, J.H., de Boer, M.J., 2006. Impact of statin therapy at discharge on 1-year mortality in patients with ST-segment elevation myocardial infarction treated with primary angioplasty Atherosclerosis. 189, 186-192.

Dutcher, J., Kahn, J., Grines, C., 2007. Comparison of left ventricular ejection fraction and exercise capacity as predictors of two- and five-year mortality following acute myocardial infarction. Am. J. Cardiol. 99, 436-441.

Elwood, P.C., Sweetnam, P.M., 1979. Aspirin and secondary mortality after myocardial infarction. Lancet. 314, 1313-1315.

Gottlieb, S., Moss, A., Mcdermott, M., Eberly, S., 1992. Interrelation of left ventricular ejection fraction, pulmonary conjestion and outcome in acute myocardial infarction. Am. J. Cardiol. 69, 977-984.

Gruber, A., Smith, R., Barker, B., Sithole, J., Thomson, G.A., Idris, I., 2007. Serum urea and total cholesterol independently predict re-hospitalisation with a cardiac-related event following an acute ST-elevation myocardial infarction. Eur. J. Int. Med. 18, 531-534.

Huczek, Z., Kochman, J., Filipiak, K., Horszczaruk, G., Grabowski, M., 2005. Mean platelet volume on admission predicts 1mpaired reperfusion and long-term mortality in acute myocardial infarction treated with primary percutaneous coronary intervention. J. Am. Coll. Cardiol. 46, 284-290.

Jain, H., Avasthi, R., 2004. Correlation between dispersion of repolarization (QT dispersion) and ventricular ectopic beat frequency in patients with acute myocardial infarction: A marker for risk of arrhythmogenesis? Int. J. Cardiol. 93, 69-73.

Kodama, K., Sakagashira, S., Hori, M., 1996. Prognostic significance of diabetes mellitus in patients with acute myocardial infarction after recanalization. Diabetes Res. Clin. Pract. 30, 1-75.

Kuch, M., Janiszewski, M., Mamcarz, A., Cudnoch-Jedrzejewska, A., Dłuzniewski, M., 2009. Major adverse cardiac event predictors in survivors of myocardial infarction with asymptomatic left ventricular dysfunction or chronic heart failure. Med. Sci. Monit. 15, 40-48.

Kyung, H.C., Myung, H., Youngkeun, A.., Korea Acute Myocardial Infarction Registry (KAMIR) Investigators, 2010. Low-density lipoprotein cholesterol level in patients with acute myocardial infarction having percutaneous coronary intervention (the cholesterol paradox) Am. J. Cardiol. 106, 1061-1068.

Lewis, S.J., Sacks, F.M., Mitchell, J.S., 1998. Effect of pravastatin on cardiovascular events in women after myocardial infarction: The cholesterol and recurrent events (CARE) trial. J. Am. Coll. Cardiol. 32, 140-146.

Libby, P., 2000. Coronary artery injuty and the biology of atherosclerosis: Inflammation, thrombosis, and stabilization. Am. J. Cardiol. 86, 3-9.

Lopes, N.H., Paulitsch, Fd. S., Gois, A.F., Pereira, A.C., Stolf, N.A., Dallan, L.O., 2008. MASS study. European Journal of Cardio-Thoracic Surgery. Volume 33, Issue 3, March 2008. 349-354. doi: 10.1016/j.ejcts.2007.11.025.

Malmberg, K., Bavenholm, P., Hamste,n A., 1994. Clinical and biochemical factors associated with prognosis after myocardial infarction at a young age. J. Am. Coll. Cardiol. 24, 592-599.

Özgül, A., Atar, İ., Bal, U.A., Ertan, Ç., Aydınalp, A., Gülmez, Ö., Müderrisoğlu, H., Özin, B. 2007. Koroner arter hastalığı ve metabolik sendromu olan hastalarda QT süresi ve yayılımı Türk Aritmi. Pacemaker ve Elektrofizyoloji Dergisi. 5, 231-237.

Paventi, S., Bevilacqua, U., Parafati, M., Luzio, E., Rossi, F. 1999. QT dispersion and early arrhythmic risk during acute myocardial infarction. Angiology. 50, 209-211.

Rodriguez, A., Bernardi, V., Navia, J., Baldi, J., Grinfeld, L., Martinez, J.,Vogel, D., Grinfeld, R., 2001. ERACI II, Journal of the American College of Cardiology, Volume 37, Issue 1. 51-58.

Schoene, N.W., 1997. Design criteria: Tests used to assess platelet function. Am. J. Clin. Nutr. 65, 1665-1685.

Schwartz, P.J., Periti, M., Malliani, A. 1975. The long QT syndrome. Am. Heart. J. 89, 378-380.

Somberg, J.S., Molnar, J., 2002. Usefulness of QT dispersion as an electrocardiographically derived index. Am. J. Cardiol. 89, $291-294$.

Trowbridge, A., Slater, D., Kishk, Y.T., Martin, J., 1985. High mean platelet volume after myocardial infraction. B.M.J. 290 , $238-239$.

Van de loo, A., Arendts, W., Hohnloser, S.H., 1994. Variability of QT dispersion measurements in the surface electrocardiogram in patients with acute myocardial infarction and in normal subjects. Am. J. Cardiol. 74, 1113-1118.

Wang, C.L., Lee, W.L., Wu, M.J., Cheng, C.H., Chen, C.H., Shu, K.H., 2002. Increased QTc dispersion and mortality in uremic patients with acute myocardial infarction. Am. J. Kidney. Dis. 39, 539-548.

Yang, A., Pizzulli, L., Luderitz, B., 2006. Mean platelet volume as marker of restenosis after percutaneous transluminal coronary angioplasty in patients with stable and unstable angina pectoris. Throm. Res. 117, 371-377.

Zaputovic, L., Mavric, Z., Zaninovic-Jurjevic, T., Matana, A., Bradic, N., 1997. Relationship between QT dispersion and the incidence of early ventricular arrhythmias in patients with acute myocardial infarction. Int. J. Cardiol. 62, 211-216. 